\title{
Kıbrıslı Mehmed Kâmil Paşa'nın Layihasına Göre XX. Yüzyıl Başında Balkanlar’da Güç Dengesi
}

The Balance of Power in the Balkans According to Mehmed Kamil Paşa's Report at the Beginning of the XX. Century

\section{Hüseyin H. ALADAĞ}

Tarih Bölümü, KTO Karatay Üniversitesi, Konya, Türkiye

\section{Özet}

Osmanlı tarihinin birçok döneminde yetkili ve etkili devlet adamları ve ulemanın Padişahlara çeşitli vesilelerle arzlar, tahrirat, risaleler ve raporlar sundukları bilinen bir husustur. Osmanlı Devleti'nin XIX. ve XX. yüzyıllarında padişahlara sunulan bu metinlerin genel ismi layiha olarak adlandırılmıştır.

Son dönem Osmanlı Sadrazamlarından olan Mehmed Kamil Paşa'nın Aydın Valisi olduğu dönemde kaleme almış olduğu layihası makalemizin asli konusunu teşkil etmektedir. Bu layiha Makedonya Meselesi'nin Devleti Aliye'nin lehine nasıl çevrilebileceği hususunun ağırlıklı olarak incelendiği bir raporlamadır. Mehmet Kamil Paşa bu meseleyi büyük devletlerin çıkar çatışmalarının ekseninde ele alıp II. Abdülhamid'e arz etmiş ve çeşitli çözüm yolları da teklif edebilmiştir. Layiha, tarafımızdan Balkanlar'da güç dengesi perspektifinden analiz edilmeye çalışılmıştır.

Anahtar Kelimeler: Sadrazam, Mehmed Kamil Paşa, Layiha, II. Abdülhamid, Balkanlar, Makedonya Meselesi, Batılı Devletler

\section{Abstract}

Ottoman statesmen and scholars, authoritative and influential in many periods of history on several occasions to the sultan of offerings, tahrirat, treatises, pleadings, and that they offer a known issue. One of the viziers Mehmed Kamil Pasha in the period of the Ottoman Governor of Aydın when the original topic of our article was a written report constitutes. This work's main aim was to could be solve to the "Macedonia Problem" how. Mehmet Kamil Pasha of the major States of the matter and presented to abdülhamid II on the axis of a conflict of interest, and has been able to offer various solutions. This report to be analyzed by us from the perspective of the balance of power in the Balkans, has been studied.

Keywords: Grand vizier, Mehmed Kamil Pasha, Report, II. Abdülhamid, The Balkans, Macedonia Problem, Western States.

CONTACT : Hüseyin H. ALADAĞ, hhilmialadag42@gmail.com

Geliş Tarihi : 02.12.2016

Kabul Tarihi : 31.12.2016 


\section{Giriş}

Kıbrıslı Mehmet Kamil Paşa, II. Abdülhamid'in saltanatı döneminde 25 Eylül 1885 - 4 Eylül 1891, 2 Ekim 1895 - 7 Kasım 1895 ve 5 Ağustos 1908 - 14 Şubat 1909 tarihleri arasında ve V. Mehmet Reşad'ın devri saltanatında 29 Ekim 1912 - 23 Ocak 1913 tarihleri arasında dört dönem içinde toplamda altı yıl dokuz ay yirmi gün sadrazamlık yapmış ve üst düzey bürokrasinin muhtelif kademelerinde mühim vazifelerde bulunmuş bir Osmanlı devlet adamıdır. Doğum tarihini tespit noktasında farklı görüşler olmakla beraber Kıbrıs Gazetesi'nde vefatından sonra yayımlanan terceme-i haline göre; H.1248 tarihinde (1832 veya 1833) Lefkoşa'da doğmuştur. Bugün halen Kuzey Kıbrıs Türk Cumhuriyeti sınırları içinde bulunan Gaziler Köyü'nden Topçu Yüzbaşı Salih Ağa'nın oğludur. Kıbrıs'ta başladığı mektep hayatına, Mısır'da devam etmiş, Elsine Medresesi'nde ve Kahire'de Harp Mektebi'nde okuyarak, Arapça, Farsça, Rumca ve Fransızca öğrenmiştir. ${ }^{1}$

Memuriyet vazifesine, o tarihlerde Kavalalı Mehmed Ali Paşa ahfadından gelen Hidivlerin idare ettikleri Mısır'da başlamıştır. Burada Abbas Paşa'nın yanında mütercim ve kâtiplik görevini ifa etmiştir. Mısır'da takribi olarak on yıl görev yaptıktan sonra, 1860 tarihinde Osmanlı Devleti hizmetine geçmiştir. Kıbrıs Adası Evkaf Müdürlüğü'ne, sonra Tuzla Kazası Kaymakamlığı'na, Kıbris Muhasebeciliği'ne, Sayda Muhasebeciliği'ne, bir sene sonra da Suriye Merkez Mutasarrıflı̆̆ı'na, bu görevini müteakiben de Beylerbeyilik rütbesiyle Beyrut Mutasarrıflığı'na atanmıştır. Rumeli Beylerbeyliği rütbesiyle Trablusşam Mutasarrıflığı'na, Halep Vilayeti Merkez Mutasarrıflığı'na görevlendirilmiştir. Bu vazifelerine ek olarak vilayet muavinliği ile Umur-1 Ecnebiyye Müdüriyeti hizmetini yapmıştır. 1877 tarihinde ise vezirlik rütbesiyle Kosova ve Halep valiliklerine tayin edilmiştir. Doğu Rumeli, Hersek, Kosova, Kıbrıs, Aydın gibi pek çok vilayette valilik yaptıktan sonra "Devr-i Hamidi' de" 1885 senesinde ilk kez sadrazamlığa atanmıştır. 1885 ile 1913 yılları arasında dört defa sadrazamlık yapmıştır. Son sadrazamlığı Babıâli Baskını ile neticelenmiş, istifasını Enver Paşa'nın tabancasının gölgesinde mecburen imza etmiştir. Lord Kitchener tarafından davet edildiği Kahire'de üç ay kaldıktan sonra, 1913 senesi içinde memleketi Kıbrıs'a² giderek Osmanlı siyasetinde uygun zeminin oluşmasını beklemiştir. Ancak kendisinden sonra göreve getirilen Mahmud Şevket Paşa'nın bir komplo ile öldürülmesi ve İttihatçıların muhalif siyasetçileri sürgün etmeye başlamaları ile ümitleri iyice kaybolmuştur. Bundan sonra sürgün edilenler arasında bulunan ailesi de Kıbrıs'a Mehmed Kamil Paşa'nın yanına gelmiştir. Kıbrıslı Mehmed Kamil Paşa bu dönemde, İngiltere'ye gitmeye hazırlanırken, 14 Kasım 1913 tarihinde geçirdiği bir "sekte-i kalp" neticesinde vefat etmiş ve cenazesi Lefkoşa Arap Ahmed Paşa Camii haziresine defnedilmiştir. ${ }^{3}$

\footnotetext{
${ }^{1}$ Mehmet Demiryürek, "Sadrazam Kıbrıslı Kamil Paşa hakkında bazı notlar ve Kamil Paşa'nın terekesi", Ankara Üniversitesi Dil ve Tarih-Coğrafya Fakültesi Tarih Bölümü Tarih Araştırmaları Dergisi, Cilt: 25, Say1: 40, s. 59-105

${ }^{2}$ Mehmed Kamil Paşa'nın memleketi olan Kıbrıs esasen 1878'den itibaren İngiliz idaresine girmişti.

${ }^{3}$ Nazım Tektaş, Sadrazamlar Osmanlı'da İkinci Adam Saltanatı, Çatı Yayınevi, İstanbul, 2002, s. 650-662, Ayrıca Bkz. Mustafa Birol ÜLKER, "Mehmed Kamil Paşa (Kıbrislı)", Yaşamları ve yapttlarıyla Osmanlılar Ansiklopedisi, Cilt: II, YKY, İstanbul, 1999, s.147-148
} 


\section{Layihanın Analizi ve Mehmed Kamil Paşa'nın Teklifleri}

Makalemize konu olan belge Başbakanlık Osmanlı Arşivi'nde Y.EE. 86-29 künye ve numara ile kayıtlı olup, 13 Haziran 1905 (H.9/R/1323) tarihinde, o zaman Aydın valisi olan Kıbrıslı Mehmed Kamil Paşa tarafından Mabeyn-i Hümayun Baş Kitabeti'ne sunulmuştur. Belge 2,5 varak ve bir takdimden ibarettir. ${ }^{4}$

Balkanlardaki karmaşa ve Milliyetçi rekabet tavizsiz bir biçimde Makedonya Meselesinde kendini iyiden açı etmiştir. Düvel-i Muazzama bu siyasal karmaşa ortamında çıkarlarına uygun stratejiler belirlemişlerdir. Esasen Selanik, Kosova ve Manastır hudutlarını ihata eden Makedonya'da, ilk başlarda "çözümü kolay" gibi addedilen problem giderek karmaşıklaşmış ve politik bir açmaza doğru evirilmişti. Makedonya'nın en temel zorluğu kozmopolit oluşuydu. Onca dini ve etnik fraksiyonun tesis ettiği lisan ve kültür farklılıklarına ilaveten "hudutlar" konusundaki muğlâk kalan ya da mutabakata varılamayan hususlar işi oldukça belirsizliğe sürüklemişti. Bulgarların arasında hızla yayılan milliyetçi bakışın bölgede yüzyıllardır devam eden sakinliği sona erdireceğini tahmin edemeyen yoktu. Bulgar Kilisesi'nin güya Yunanlılara karşı bir tedbir olmak üzere Babıâli tarafından teşvik ve teşkili bu kargaşayı hızlandırıcı katalizör vazifesi görmüştü. ${ }^{5} 1890$ tarihine gelindiğinde bölgedeki rekabet ve entrikalar son haddine varmıştı. Makedonya'da 1903 senesinde çıkan kalkışmanın nihai hedefinin bölgede Osmanlı idaresini bitirmek olduğu açık olsa da Rusya Bulgarları ayaklanmayı desteklememesi noktasında ikaz etmişti. ${ }^{6}$ Rusya'nın böyle bir politikaya meyletmesinde İstanbul'da hükümetle arası iyi olan Rus sefir Zinoviev'in katkısı çok olmuştu. Almanya ve Avusturya da bağımsız Makedonya düşüncesi içinde değillerdi. İngiltere ise durumu yakından takip ediyor ve bölgeye Hıristiyan yönetici ve yönetici yardımcıları atanmasını istiyordu. Mürzsteg' de yapılan "Makedonya sorunu için reform paketi" toplantısında Rusya ve Avusturya'da kendilerinden birer yardımcı bulunmasını teklif ederek İngiliz Hariciyesinin bu teklifini zayıflatmış oluyorlardı. İngiliz Landsowne daha da ileri giderek Osmanlı güçlerinin Makedonya'dan çekilmesi ve bölgenin her bir kısmının Güçlü devletlerin arasında uzlaşılarak paylaşılıp kontrolünü teklif etmişti. İngiltere dışında hiçbir devlet bu teklife sıcak bakmadı. Yine de pek çok "reform" isteğini Osmanlı mecburen kabul etti. Yıllarca sürüncemede kalan bu reform programı Makedonya Meselesini halletmek bir yana aksine müzminleştirdi. ${ }^{7}$

İşte tam da bu dönemde Aydın valisi Kıbrıslı Mehmed Kamil Paşa'nın kaleme almış olduğu layiha İngiltere yanlısı bir politika izlenmesi gerektiğine dair tavsiyeleri başta olmak üzere daha pek çok açıdan bu "gaileyi" ele alması nokta-i nazarından da ehemmiyet arz etmektedir. Artık bu layihayı incelemeye başlayabiliriz.

Mehmed Kamil Paşa, Osmanlı diplomatika teamüllerine uygun olarak, Padişah için yaptığı duayı layihasına girizgâh kılmıştır. Bu duasında Sultan II. Abdülhamid'e uzun ömür, maddi manevi afiyet ve her zorlukta kolaylık dilemiştir.

\footnotetext{
${ }^{4}$ BOA, Y.EE $86-29$

${ }^{5}$ Matthew Smith Anderson, Doğu Sorunu 1774-1923, (Çev: İdil Eser), YKY, İstanbul, 2010, s.280

${ }^{6}$ A.g.e, s. 281

${ }^{7}$ A.g.e, s. 282
} 
Bundan sonra Kamil Paşa, Rusya Devleti'nin Uzak Doğu'da Japonya karşısında almış olduğu mağlubiyetin onlar için büyük bir hezimet olduğunu' ${ }^{8}$, neticesinde doğal olarak artık Avrupa politikasının başka bir istikamette dönüştüğünü, Makedonya Meselesi'nin gündemin birinci maddesi olmaktan çıkıp, Rumeli'de ecnebi devletlerin müdahalelerinin son bulduğuna değinmiştir. ${ }^{9}$ Mehmed Kamil Paşa, bu politik atmosferde Balkanlardaki statükonun muhafaza edilebilmesi için o günkü şartlara uygun bir yol tutulmasını ve bu manada münasip bir politika tespit edilmesi gerekliliğini işaret etmiştir. Layihasının hemen bu kısmında; geliştirilmesi zaruri politikanın stratejisinin tayininden evvel; II. Abdülhamid'e bazı hususları arz etmek istediğini belirtmiş ve şöyle devam etmiştir: İngiltere'nin dostluğundan faydalanılacak, düşmanlığından kaçınılacak bir devlet olduğunu, uzun bir dönem içinde İngilizlerin izledikleri emperyalist politikalarıyla variyetli ve etkin bir devlet haline geldiklerini belirtmiştir. Bu devletin ticari menfaatlerini koruyup gözetene, takviye edene, hiç olmazsa mani olmayana o dönemlik dost olmakla hukuklarını muhafaza ettiğini tespit etmiştir. Aksi hallerde ise bu devletin (İngiltere) birçok tedbir ve hesap yaparak büyük bir düşman kesildiğini ifade etmiştir. Osmanlı Devleti sınırları içinde hiçbir başka devletin politik üstünlügünü, tesirini ve rekabetini hazmetmeyen İngiltere'nin, demiryolu inşaasının Almanlara ve Fransızlara verilmesine de çok tepkili olduklarını belirtmiştir. Dahası savaş gemileri ve silahların siparişlerinde İngiltere'ye müracaat edilmemesini içten içe çekemeyerek artık Devlet-i Aliye'den yüz çevirdiğini de eklemiştir. ${ }^{10}$

Kamil Paşa layihasında Osmanlı Devleti açısından meselelerin çözüme kavuşturulması ve sıkıntıların giderilmesi noktasında, bilhassa Makedonya Meselesi'nin halli hususunda İngiltere ile mutabakatın elzem olduğunu da vurgulamıştır. Hatta bu yakınlaşmanın önemini beyan sadedinde; diğer devletlerin tümü birlik olsalar da yalnız İngiltere muhalefet etse, meselenin halledilemeyeceğini vurgulamıştır. Hâlbuki aynı konuda İngiltere Devleti meselenin halledilmesine müteveccih reyde bulunsa diğer tüm devletler muhalif kalsa, problemin çözülmesine İngilizlerin politik iktidarlarının kâfi geleceğine inanmıştır. Burada Mehmed Kamil Paşa, İngiltere'nin dostluğunu kazanmanın devletin faydasına, sıkıntının giderilmesine yarayacağını vurgularken bir de fetva çıkarmıştır. Raporunda bu fetva; “Devlet-i İslamiye'nin menfaati için düşmanla dost görünmek caizdir" cümleleriyle yer almıştır.

Kıbrıslı Mehmed Kamil Paşa, Makedonya Meselesi'nde, Fransa'nın güdümlü bir devlet olarak İngiltere'nin politik yörüngesinden çıkmayıp yönlendirmesinden ayrılmayacağını ifade etmiştir. İtalya'nın ise Latin mezhebine mensup güruhtan

\footnotetext{
8 Rusya Uzakdoğu'da Japonya ile 1904-1905 yılları arasında büyük bir savaşa tutuşmuş ancak tüm beklentilerin aksine ciddi bir mağlubiyet yaşamıştır. Japonlar bu savaşta, Uzakdoğu'da hesapları olan ve çıkarları Rusya ile çatışan İngiltere ile A.B.D 'den hatırı sayılır destekler görmüştür. Bkz. Hüseyin Hilmi Aladağ, 1904-1905 Rus- Japon Savaşı ’nın Osmanlı Kamuoyundaki Yansımaları, Niğde Üniversitesi Sosyal Bilimler Enstitüsü Yayınlanmamış Y. Lisans Tezi, 2011

${ }^{9}$ II. Abdülhamid'in genel anlamda bu fikre iştirak etmediğini ve meseleyi bir başka cepheden ele aldığını burada ifade etmeliyiz. II. Abdülhamid Rusların "Trans Sibir Projelerini” akamete uğratan Japon yenilgisi nedeniyle tekraren tüm dikkatlerini Balkanlara teksif edeceklerini ve bu coğrafyayı iyice karıştıracaklarını düşünmüştür. Dolayısıyla, İngiltere için görünürde gündemin birinci sırasından düşen Makedonya meselesinin Rusların tekraren politik bakımdan Balkanlara yönelmesi ile alevleneceğini hesap edebilmiştir. Bkz. Oral Sander, Illkçağlardan 1918'e Siyasi Tarih, İmge Yay., Ankara, 1989, s. 185

${ }^{10}$ Aynı Belge, s. 2
} 
menfaatlenmek hesapları yapsa da Rumeli'de statükonun muhafazası kararına itiraz etmeyeceğini tahmin etmiştir. Mehmed Kamil Paşa Almanya'nın ise her halükarda Osmanlı Devleti yanında yer alacağını düşünmüştür. Avusturya'nın da Makedonya Meselesi'nde Rusya olmadan tesirsiz kalacağını, Bulgaristan'ın ise barışı bozacak resmi bir girişimde bulunamayacağını beyan etmiştir. ${ }^{11}$

Daha önce Rusya ve Avusturya birtakım 1slahatları teklif ederken, İngiltere arka çıkmış, daha da ileri giderek Edirne Vilayeti'ni de ıslahat meselesine katmak istemişti. İngiltere'nin bu teklifinin bize politik bakımdan "soğuduğunu" hissettirmek maksadıyla yapılmış olduğunu söyleyen Mehmed Kamil Paşa esasında meselenin öyle olmadığını ifade ederek şöyle devam etmiştir. Makedonya Bulgaristan ile birleşirse, Rusya'nın Bulgarlar ile olan akrabalığından mülhem Karadeniz'den Boğaza, Boğazdan Edirne'ye ve Dedeağaç’a kadar tüm hattı işgal edip, bir set teşkil etmek azminde olduğunu belirtmiştir. Buna mani olmak isteyen İngiltere'ye bu husus dikkate alınarak yakınlaşılabilir ve İngiltere'nin Dersaadet sefiri ile müzakereler başlatılabilir ise İngiltere ile yeniden yakınlaşılabilir şeklinde teklif getirmiştir. Kamil Paşa layihasında; Bulgar komitacılarını el altından destekleyenlerin yalnızca Bulgar Hükümeti değil aynı zamanda Rusya olduğunu, Rusya'nın Avusturya'yı da yedeğine alarak üç vilayet için (Selanik, Manastır ve Kosova) 1slahat talebi olduğunu ortaya koymuştur. Kamil Paşa tavsiyelerine şunu da ilave etmiştir: Makedonya'nın idaresinde tüm cemaatler hakkında eşitliğe aykırı, ayrımcı bir muamelede bulunulmamasının, bu zikredilen yerlerde tebaanın Osmanlı düzen ve kanunlarına uygun hareket etmelerini temin edeceğini beyan etmiştir. ${ }^{12}$

Kıbrıslı Mehmed Kamil Paşa neticede; tüm bu konularda İngiltere'yle bir ittifak ve muvafakat temin etmenin gereğini ifade etmiştir. Politikaların bu hassasiyete uygun belirlenerek yürütülmesini tavsiye etmiştir. Bu manada İngiltere ile münasebetlerin yenilenmesi gerekliliğini hatırlatmıştır. Zira devletlerarası ilişkilerde "kin tutmak" diye bir şeyin olmadığını, bir menfaat platformu tespit edilebilirse, birlikte bu menfaat platformu üzerinde "eski dostmuş gibi" politikaların şekillendirilebileceğini de raporuna eklemiştir. Tam da bu dönemde giderek büyüyen Yemen sıkıntısının dahi İngiltere'nin bu tazelenen dostluğu vesile kılınarak kolayca halledilebileceği, fırsatların kaçırılmaması gerektiğinin âcizane mütalaası ve tavsiyesi olduğunu ifade etmiştir. Görüşlerini raporunda serdeden Mehmed Kamil Paşa yine de Hilafet makaminda bulunan zat-1 şerifin (Sultan II. Abdülhamid) Allah'ın izniyle bu meselelerle ilgili her ne karar verirse hikmetlerin ve isabetlerin bu istikamette olduğuna imanının tam olduğunu vurgulamak suretiyle layihasını neticelendirmiştir. ${ }^{13}$

\section{Sonuç}

Osmanlı Devlet adamları bazı mühim hadiseler hakkındaki kanaatlerini Osmanlı Sultanlarına layihalar kaleme almak suretiyle de sunabilmişlerdir. II. Abdülhamid dönemi Aydın Valisi Mehmed Kamil Paşa da bu meyanda; "Makedonya Meselesi ve Balkanlarda mevcut statüko" üzerinden birtakım siyasi analizlerde bulunmuştur. Böylece kendi görüşüne göre teklifler getirmiş ve alınmasını zaruri gördüğü birtakım

${ }^{11}$ Aynı Belge, s. 2

12 Aynı Belge, s. 3

${ }^{13}$ Ayn1 Belge, s. 4 
tedbirleri sıralamıştır. Mehmed Kamil Paşa'nın layihası mevzu her ne kadar Balkanlar olsa da kendi siyasi yakınlığı da hesaba katıldığında meselenin merkezine "Balkanlarda güç dengesi" üzerinden İngiltere'yi almıştır. Mehmed Kamil Paşa, işin içine İngiltere katılmadan yani İngiltere'nin siyasi desteği elde edilmeden Balkanlarda arzu edilen neticenin alınamayacağını bilhassa vurgulamıştır. M. Kamil Paşa Balkanlar için teklif ettiği siyasi denklemde, nüfuz yani etki sahaları bakımından tüm devletleri bir tarafa ve İngiltere' yi ise ayrıcalıklı olarak tek başına değerlendirmiştir. "Tüm devletler bir konuda mutabakata varır fakat İngiltere farklı bir reyde bulunacak olursa, mutlak surette mesele İngiltere'nin istediği yönde şekillenir" diyebilecek kadar bölgede hatta dünyada İngiltere'nin uluslararası ilişkilerde dominant konumu olduğunu iddia etmiştir. Mehmed Kamil Paşa'nın raporu gerçekten modern uluslararası ilişkiler disiplininin "rasyonel" ve "pragmatist" duruşuna yaklaşmış görünmektedir.

\section{KAYNAKÇA}

\section{Arşiv Belgesi:}

BOA, Y.EE 86-29 Numaralı Belge

\section{Diğerleri:}

Aladağ, Hüseyin Hilmi, 1904-1905 Rus- Japon Savaşı'nın Osmanlı Kamuoyundaki Yansımaları, Niğde Üniversitesi Sosyal Bilimler Enstitüsü Yayınlanmamış Y. Lisans Tezi, Niğde, 2011

Anderson, Matthew Smith, Doğu Sorunu 1774-1923, (Çev: İdil Eser), YKY, İstanbul, 2010.

Demiryürek, Mehmet, "Sadrazam Kıbrıslı Mehmet Kâmil Paşa Hakkında bazı Notlar ve Kâmil Paşa'nın Terekesi", Ankara Üniversitesi Dil ve Tarih-Coğrafya Fakültesi Tarih Araştırmaları Dergisi, Cilt: XXV, Sayı: 40, Eylül 2006.

Sander, Oral, İlkçağlardan 1918'e Siyasi Tarih, İmge Yayınları, Ankara, 1989.

Tektaş, Nazım, Sadrazamlar Osmanlı'da İkinci Adam Saltanatı, Çatı Kitapları, İstanbul, 2002

Ülker, Mustafa Birol, "Mehmed Kamil Paşa (Kıbrıslı)", Yaşamları ve Yapıtlarıyla Osmanlilar Ansiklopedisi, C.II, YKY, İstanbul, 1999. 


\title{
EK-1: BOA, Y.EE 86-29 NUMARALI BELGENIN TRANSKRIPSIYONU:
}

\author{
Aydın Vilâyeti
}

Husûsî

Mâbeyn-i Hümâyûn-ı mülûkâne Baş Kitâbet-i Celîlesine

Devletlü Efendim Hazretleri

Leffen takdîm kılınan arîzanın ehemmiyetine mebnî meşmûl-i nigâh-ı âlî-i hazret-i veliyyü'nni'met-i a'zamî olabilecek bir vakt-i münâsibde arzı mütemennâ-yı âcizîdir. Olbâbda emr u fermân hazret-i men-lehü'l-emrindir. Fî 9 Rebî'u'l-âhir sene 323 ve 30 Mayıs sene 321

Vâlî-i Aydın Mehmed Kâmil bin Sâlih.

\section{[2]Aydın Vilâyeti}

\section{Husûsî}

Hakk Celle ve âlâ hazretleri velîni'met-i bî-minnetimiz pâdişâhımız efendimiz hazretlerine tûl-i ömür ve kemâl-i âfiyet ihsân ve her müşkili âsân buyursun.

Rusya devletinin aksâ-yı şarkda hezîmet-i ahîre-i külliyyesiyle Avrupa politikası tab'an tağyîrpezîr olduğundan bu meyânda Makedonya mes'elesi dahi ehemmiyetten düşmüş ve Rumeli'de ecnebî devletlerin müdâhalelerine nihâyet verilerek hukûk-ı mukaddese-i şâhâne ile istatükonun muhâfazası devlet-i aliyyelerince hâl-i hâzıra muvâfık bir meslek-i siyâsî ittihâzına vâbeste bulunmuşdur. Ta'yîn-i meslekden evvel şurasını arza cesâret ederim ki ingiltere devleti dostluğundan istifâde düşmanlığından istî́âze olunacak bir millet olup müstağnî-i arz olduğu üzere bu devlet memleketinin menâfi'-i ticâriyyesini tervîc edenlere dost olarak onların muhâfaza-i hukûklyyelerine sa'y ve ikdâm ve aksi takdîrde def'-i haylûlete hasmâne vefkda müdebbirâne ihtimâm eder. Memâlik-i şâhânede hiçbir devletin kendisine tefevvuk-ı nüfûz ve rekâbetini çekemeyen ingiltere devleti ba'zı vilâyât-ı şâhânede Almanyalılara ve Fransızlara şimendüfer inşâsı imtiyâzâtı verilip ingilizlere dirîğ buyurulmasından ve süfün-i harbiye ve esliha sipârişlerinde ingiltere fabrikalarına mürâca'at olunmamasından ve'l-hâsıl mu'âmelât-ı sâ'irede sevâbıkı vechile yüz bulmamasından muğber olmasıyla devlet-i Aliyyeden yüz çevirmiş ve mesấ'ili siyâsiyyede müşkilât-ı vâkı'anın dostâne halline mu'âvenet edeceği yerde sûret-i hasmânede teşdîdine ve daha ba'zı gavấil ihdâsıyla iğbirârının temdîdine sarf-ı mesâî etmekde olup ezcümle Yemen gâ'ilesi devlet-i müşârun ileyhin ihtirâ'-kerdesi olduğu şüphesizdir. Eğerçi Devlet-i Aliyyeleri hall-i mesấil ve def'-i gavâ'il içün diğer bir iki devletin mu'âvenetine ihtiyâcı olmamış olsa ingiltere devleti dostluğuna meyl edecek bir millet değil ise de ne çâre ki meselâ mevzû' bahs olan Makedonya mes'elesinin merzîi şâhâne vechile halli husûsunda düvel-i mufahhame-i sâ'ire hem-ra'y ve hem-efkâr olub da ingiltere devleti muhâlif ra'yde bulunsa mes'eleye karâr verilemez. Hâlbuki aynı mes'elede ingiltere devleti düvel-i sấireden üçünü kendi tarafına celb ile diğer devletler muhâlif ra'yde bulunarak hâricde kalmış olsalar o mes'ele karâr-gîr olub hükm-i karâr icrâ olunur. Ingiltere'nin şâyân-ı arz bir hâli vardır ki bir devlet hakkında iğbirâr veya husûmeti kendi menâfi'inin zıyâ'ı müddetine mahsûs olub ta'kîb ettiği menfa'at hâsıl olur olmaz derhâl tebdîl-i meslek ederek husûmeti dostluğa mübeddel olur. Binâ'enaleyh devlet-i müşârun ileyhânın dostluğunu kazanmak müşkil olmayıp maslahat-ı devlet içün def'-i mazarrat veya celb-i menfa'at zımnında bir hasma müdârâ etmek câ'iz olduğundan devleteynin menfa'atini mûcib ba'zı teşebbüsât-ı nâfı'ada ingiltere'nin arzusuna mümâşât olunması hikmet-i hükûmete muvâfık 
olur. Bu sûretle devlet-i aliyyeleriyle ingiltere devleti beyninde emniyet ve meveddet-i muktaziyenin husûlünü müte'âkıb çünki Fransa devletinin Makedonya'da hiçbir menfa'ati olmadığı gibi politikaca ingiltere ile i'tilâf-ı tâm üzere bulunması hasebiyle Makedonya mes'elesinde ingiltere'nin ra'yinden ayrılmayacağı bedîhî olub italya devleti Makedonya'nın teşettütü hâlinde Arnavudluğun ahâlîsi Latin mezhebinde bulunan kısmına müdâhale ile hissemend-i menfa'at olmak arzusunda bulunsa da Rumeli'nde istatükonun muhâfazası karârına iltihâk edeceği derkâr ve Almanya devleti zâten devlet-i aliyyelerine meclûb olub Avusturya devleti ise Makedonya mes'elesinde Rusya'sı bir şey yapamayıp Rusya devletine gelince Rumeli vilâyât-ı şâhânesi hakkında olan menviyyâtını şu hâl-i pür-melâlinde mevki'-i tatbîka îsâl edecek nüfûz ve iktidârı hâ'iz olmadığı cihetle işi tatlı yerine bağlamak isteyeceği ve Bulgaristan dahi bi'ttebe'ıyye devlet-i metbû'asına vesâ'ir devletlerin arzusuna karşı sulhü ihlâl edecek hâl ve harekette bulunamayacağı âşikâr olduğundan olbâbda Ingiltere'nin vesâtat-i sulh-perverânesine bi'I-mürâca'a vilâyât-ı mezkûrede devlet-i aliyyelerince icrâsına bed' olunan ıslâhât ile Rusya ve Avusturya devletlerince tensîb ve teklîf olunan mukarrerâttan kâbil-i tatbîk olanlar mevki'-i icrâya vaz'[3]olunmuş olmasıyla usûl-i mevzû'anın devâmına devlet-i aliyyelerince i'tinâ olunmak üzere devleteyn-i müşârun ileyhimâ'nın müdâhalalerine nihâyet verilmesi sûreti ingiltere ile beynenâda hâlisâne müzâkereye girişilse gerçi devlet-i müşârun ileyhânın bundan evvel ıslâhât teklîfinde Rusya ve Avusturya'ya kuvvetü'z-zahr olarak işin daha ilerisine gidip Edirne Vilâyetini dahi ıslâhât mes'elesine idhâl etmek istemiş ve bu teklîf zâhiren Ingiltere'nin devlet-i aliyyeleri hakkında olan iğbirârını bize hissettirmek sûretinde görünmüss ise de hakîkat-i hâl öyle olmayıp Makedonya'nın Bulgaristan ile birleşmesi hâlinde âtiyen gerek devlet-i aliyyelerinin Bulgaristan'a ve gerek Bulgarların Istanbul cihetine tecâvüzlerine meydân vermemek bahânesiyle Rusya'nın Karadenizde vâki' boğazdan Edirne'ye ve Edirne'den Dedeağaç'a kadar olan hattı işgâl-i askerîsi tahtına alıp bu vechile tarafeyn beyninde bir mıntıka-i mâni'a teşkîl etmek azminde bulunduğu mukaddemce teraşşuh etmiş idüğünden vakten mine'l-evkât Rusya'nın o misillü teşebbüsât-ı desîse-kârîsine mahall kalmamak maksad-ı dûr-endişsiyle ingiltere devleti Edirne vilâyetini dahi Makedonya ile karâr-ı düvelî tahtına almak emelinde bulunduğu meczûm olduğundan şu hâlde mes'elenin Rusya ve Avusturya'nın arzuları vechile hıtâm bulmasından ise devlet-i aliyelerine hüsn-i müâsebetini te'yîd içün marzâ-i âlî-i cenâb-ı şehriyârîleri dâ'iresinde tesviye-pezîr olmasını tercîh edeceği şüphesizdir. Sûret-i mu'âmele rehîn-i tasvîb-i âlî olduğu hâlde ingiltere ile tecdîd-i münâsebât olunmasını müte'âkıb devlet-i müşârun ileyhânın Dersa'âdet sefîri ile Makedonya mes'elesi vaz'-ı mevki'-i müzâkere edilerek Giridliler taht-ı idâre-i devlet-i aliyyede iken ba'zı ıslâhât ve müsâ'adât mutâlebâtını vesîle ittihâzıyla ara sıra ihtilâle ictisâr ve teskîn-i hâl içün devlet-i aliyyeyi nederece fedâkârlığa dûçâr eyledikleri vâreste-i tezkâr olub şimdi ise kendi cinslerinden bir prensin idâresinde ve dört devletin nezâreti tahtında bulundukları hâlde yine hâl-i ahvâl-i sâbıkanın aynı olarak Girid'in Yunanistan'a ilhâkı talebiyle ref'-i livâ-yı ısyân eyledikleri ve hâkezâ Bulgarı mukaddemâ Ceneral Ignatiyef'in kurmuş olduğu plan üzere taraf taraf idâre-i devlet-i aliyyeden şikâyete kıyâm ile vukû'a gelen ihtilâlât ve muhârebât netîcesinde Rusya ile akdolunan Ayastefanos mu'âhedesini ta'dîlen Berlin konferansında bir Bulgaristan emâretiyle bir Rumeli şarkî eyâleti teşkîl olunup bu eyâlet Bulgarlar tarafından idâre olunmakda iken buna dahi kanâ'at etmeyerek düvel-i mufahhama tarafından kurulmuş olan esâsı bozup emâret ile birleşmiş oldukları misillü bu kere Bulgar komitelerinin Makedonya'ya tasallutu ve Rusya'nın Avusturya'yı ma'iyetine alarak vilâyât-ı selâse içün ıslâhât talebi şimdiye kadar Rusya'dan görülen derslerin mâ-ba'di olub maksad-ı aslî umûm Bulgarların Rusya'nın nüfûzu tahtında te'sîs eden Bulgar hükûmetinin idâresinde birleşmesi mâddesi olduğu bedîhî olduğundan Rûmeli kıt'asınca hayli tahavvülât ve müvâzene-i düveliyyece ınkılâbâtı dâî öyle bir planın kuvveden file gelmesine yardım etmekden ise icrâ'âtına sedd çekmek muvâfık-ı hükûmet olacağı mukaddemâtı ingiltere sefîrine serd ve ityân olundukdan ve eğerçi bu esnâda Rusya'nın hezîmeti üzerine Bulgar komitelerinin harekât-ı tecâvüziyyeleri kesb-i hıffet etmiş ise de tasalluttan ferâğat ettiklerine devlet-i aliyyece yakîn hâsıl olmadıkça Rûmeli'de seferber hâlinde bulunan ordû-yı hümâyûnları 
hâl-i hâzırı tahvîl edememekde olmasıyla mesârıf-i fevkalâde hazîne-i celîleye girân gelmekde olduğu beyân kılındıkdan sonra bizce bu hâle düşünülen çâre ahâlîsi yalnız Bulgar değil külliyyet üzere ecnâs-ı muhtelifeden mürekkeb olan Makedonya'nın idâresi umûmun menâfi'ine muvâfık olması lüzûmuna mebnî hiçbir cemâ'at hakkında kâ'ıde-i müsâvâtın gayrı mu'âmele olunamayıp kavânîn ve nizâmât-ı devlet-i aliye de bu esâsa mübtenî bulunduğundan vilâyât-ı mezkûrede icrâ olunan ıslâhât dấiresinde hüsn-i idâreye devlet-i aliyyece devâm olunmak üzere istatükonun muhâfazasına düvel-i mufahhamaca mu'âhede-i esâsiyyeyi te'yîden bir karâr-ı kat'î i'tâsı hâlinde Bulgarlar şu hâlde Rusya devleti kendilerine yâr ve yardımcı olamayacağını bilerek beyhûde fedâkârlık etmekden ise tasalluttan ferâğatle Makedonya'da her şey hâl-i tabîîisine ric'at edip ba'demâ Rusya ve Avusturya'nın müdâhalesine nihâyet verilmiş olunacağı merkezinde [4] idüğü dermiyân olunarak sefîr-i müşârun ileyh vâsıtasıyla ingiltere devletiyle bu bâbda bir i'tilâf-ı ra'y ve muvâfakat husûlünü müte'âkıb diğer süferâ ile de müzâkerede düvel-i metbû'alarının politikalarına göre lisân-ı münâsib isti'mâl olunarak düvel-i müşârun ileyhim beyninde tab'an cereyân edecek muhâbere üzerine merzî-i âlî-i mülûkânelerine muvâfık bir karâr husûlü me'mûl-i kavîdir. Ber-vech-i ma'rûz ingiltere devletiyle tecdîd-i münâsebât ve tahsîn-i mükâfât buyuruldukda zâten ve tabî'atinde kinîn olmayan kâr-azmûde bu devlet derhâl eski dostluğa ric'atle Makedonya mes'elesinin tesviyesine hizmet edeceği gibi devlet-i aliyyeleri lehine tahvîl-i meslek etmesiyle bu esnâda vukû'u bir gấile hükmünü almakda olan Yemen müşkilâtının dahi tesviyesi kesb-i suhûlet eyleyeceği cihetle bu bâbda fırsat fevt edilmeyerek îcâb-ı hâlin îfâsına şurû' olunması âcizâne mutâla'a olunmuş ise de zât-ı akdes-i cenâb-ı hilâfet-penâhîleri minındillâh her ne vechile mülhem olurlar ise hikmet ve isâbet anda olacağı derkâr olmağın ol-bâbda ve kâtıbe-i ahvâlde emr u fermân hazret-i men lehü'l-emrindir. Fî 9 Rebî'u'l-âhir sene 323 ve 30 Mayıs sene 321 .

Aydın Vâlîsi kulları Mehmed Kâmil bin Sâlih. 